\title{
Two are better than one on progression through MET mechanism for EGFR+ NSCLC patients
}

\author{
Waleed Kian, Laila C. Roisman, Nir Peled \\ The Legacy Heritage Oncology Center \& Dr. Larry Norton Institute, Soroka Medical Center \& Ben-Gurion University, Beer-Sheva, Israel \\ Correspondence to: Prof. Nir Peled, MD, PhD, FCCP. Head of Oncology, The Legacy Heritage Oncology Center \& Dr. Larry Norton Institute, \\ Soroka Medical Center \& Ben-Gurion University, Beer-Sheva, Israel. Email: peled.nir@gmail.com. \\ Comment on: Wu YL, Zhang L, Kim DW, et al. Phase Ib/II Study of Capmatinib (INC280) Plus Gefitinib After Failure of Epidermal Growth Factor \\ Receptor (EGFR) Inhibitor Therapy in Patients With EGFR-Mutated, MET Factor-Dysregulated Non-Small-Cell Lung Cancer. J Clin Oncol \\ 2018. [Epub ahead of print].
}

Submitted Nov 20, 2018. Accepted for publication Nov 30, 2018.

doi: 10.21037/tlcr.2018.12.01

View this article at: http://dx.doi.org/10.21037/tlcr.2018.12.01

Recent years have borne witness to the development of numerous acquired resistances to epidermal growth factor receptor (EGFR)-tyrosine kinase inhibitors (TKIs) treatment for patients with EGFR-mutated non-small cell lung cancer (NSCLC). Mechanism of resistant includes EGFR T790M, MET gene amplification $(1,2)$, transformation to small cell lung cancer and others. Approximately 5 to 26 percent of these acquired modifications occur due to dysregulation of the mesenchymal-epithelial transition factor (MET) either by amplification or overexpression patterns. Previous studies have failed to show efficacy of adding MET inhibitors to EGFR-TKI therapies upon progression (3).

Wu et al. reports in this journal that adding capmatinib to gefitinib yielded an overall ORR of $27 \%$ while a $47 \%$ ORR was reported among patients with high MET amplification ( $\geq 6$ gene copies). In addition, previous reports (3), have also reported results in the same direction. Therefore, the main challenge is patient's selection, namely optimizing precision cancer care in lung cancer.

Currently, upon progression on EGFR-TKI therapy, the most common practice is seeking only for EGFR T790M sub-mutation (4), while the presented study clearly indicates the need for widening the scope of the diagnostic approach. This study showed that MET profiling should be included for all EGFR T790M negatives reaching progression.

Moreover, the next open question would be: what is the best MET biomarker and the appropriate method of analysis? Should we use protein-based analysis by IHC, Mass Spectrometry, RNA expression levels, DNA gene amplification levels or DNA mutations found in MET? Wu et al. evaluated both MET gene amplification by FISH seeing a positive correlation, while negative for IHC. Therefore, standardization should be performed in order to better select the patients who may benefit from MET blockade on top of EGFR TKI therapy.

The efficacy of capmatinib plus gefitinib was examined by $\mathrm{Wu} e t \mathrm{al}$. in total of 161 patients. The final dose for the phase II study was capmatinib $400 \mathrm{mg}$ BID plus gefitinib $250 \mathrm{mg}$ QD. The highest efficacy with ORR of $47 \%$ was seen in patients with high MET gene amplified tumors (MET gene copy number $\geq 6$ ). Interestingly, capmatinib shows also an effect of restoring sensitivity to erlotinib and promotes apoptosis by hepatocyte growth factor pathway in NSCLC models with erlotinib-resistant (5).

In summary MET gene amplification is an escape mechanism from EGFR related therapy. Therefore, its profiling is crucial on disease progression and particularly when the T790M mutation is negative. Clinical studies should invest in their companion diagnostic, probably aimed to profile amplifications or skip mutations rather than just IHC, however further cross validation in this matter needs to be performed.

\section{Acknowledgements}

None. 


\section{Footnote}

Conflicts of Interest: The authors have no conflicts of interest to declare.

\section{References}

1. Kim S, Kim TM, Kim DW, et al. Acquired Resistance of MET-Amplified Non-small Cell Lung Cancer Cells to the MET Inhibitor Capmatinib. Cancer Res Treat 2018. [Epub ahead of print].

2. Yao D, Dai C, Peng S. Mechanism of the mesenchymal-epithelial transition and its relationship with metastatic tumor formation. Mol Cancer Res

Cite this article as: Kian W, Roisman LC, Peled N. Two are better than one on progression through MET mechanism for EGFR+ NSCLC patients. Transl Lung Cancer Res 2018;7(Suppl 4):S334-S335. doi: 10.21037/tlcr.2018.12.01
2011;9:1608-20.

3. Wu YL, Soo RA, Locatelli G, et al. Does c-Met remain a rational target for therapy in patients with EGFR TKIresistant non-small cell lung cancer?. Cancer Treat Rev 2017;61:70-81.

4. Nagano T, Tachihara M, Nishimura Y. Mechanism of Resistance to Epidermal Growth Factor ReceptorTyrosine Kinase Inhibitors and a Potential Treatment Strategy. Cells 2018;7.

5. Yano S, Wang W, Li Q, et al. Hepatocyte growth factor induces gefitinib resistance of lung adenocarcinoma with epidermal growth factor receptor-activating mutations. Cancer Res 2008;68:9479-87. 